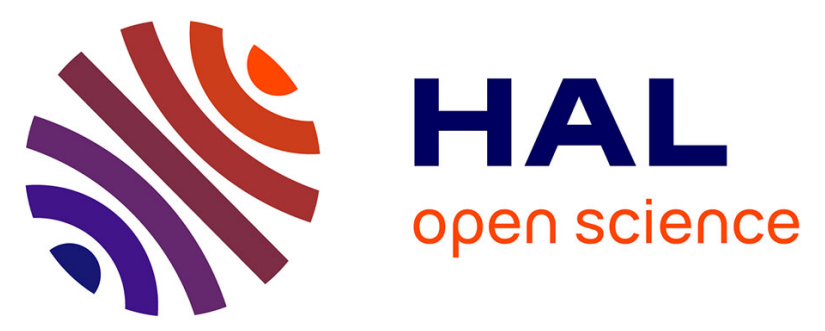

\title{
Is there any relationship between physical activity level and patterns, and physical performance in children?
}

Aurélie Blaes, Georges Baquet, Claudine Fabre, Emmanuel van Praagh, Serge Berthoin

\section{- To cite this version:}

Aurélie Blaes, Georges Baquet, Claudine Fabre, Emmanuel van Praagh, Serge Berthoin. Is there any relationship between physical activity level and patterns, and physical performance in children?. International Journal of Behavioral Nutrition and Physical Activity, 2011, 8, pp.122 - 122. 10.1249/MSS.0b013e3181824d98 . hal-01395980

\author{
HAL Id: hal-01395980 \\ https://hal.science/hal-01395980
}

Submitted on 13 Nov 2016

HAL is a multi-disciplinary open access archive for the deposit and dissemination of scientific research documents, whether they are published or not. The documents may come from teaching and research institutions in France or abroad, or from public or private research centers.
L'archive ouverte pluridisciplinaire HAL, est destinée au dépôt et à la diffusion de documents scientifiques de niveau recherche, publiés ou non, émanant des établissements d'enseignement et de recherche français ou étrangers, des laboratoires publics ou privés. 


\title{
Is there any relationship between physical activity level and patterns, and physical performance in children?
}

\author{
Aurélie Blaes ${ }^{1 \dagger}$, Georges Baquet $^{1 *}$, Claudine Fabre ${ }^{1 \dagger}$, Emmanuel Van Praagh ${ }^{2 \dagger}$ and Serge Berthoin ${ }^{1+}$
}

\begin{abstract}
Background: It is often assumed that physical activity (PA) and physical performance during childhood and adolescence are beneficial for health during adulthood, but a positive relationship between PA and physical performance has not been precisely clarified in children. The lack or the weakness of the relationships between PA and physical performance could be due to the measure of PA. If the use of accelerometry is considered as an objective and common measure of PA, the real patterns of children's habitual PA must be reflected. The aim of this study was to investigate the relationship between the levels and patterns of PA assessed with high frequency accelerometry and physical performance in young children.

Methods: Eighty-six boys and 101 girls aged 6-12 years participated in this study. Physical activity was measured over a 7-day period, using a 5-s epoch. Physical performance was assessed by means of EUROFIT tests (anthropometrics, standing broad jump, the $10 \times 5$ meter shuttle run, the sit-and-reach, the handgrip, the number of sit-ups in 30 seconds, the 20-meter shuttle run).

Results: No relationship was found between PA and physical performance. In boys only, body fatness was negatively associated with vigorous PA $(r=-0.38, p<0.001)$ and very high PA $(r=-0.35, p<0.01)$, in contrast to light PA $(r=0.28, p<0.01)$, which was positively related to body fatness.

Conclusion: In 6- to- 12 year- old children, the more active children were not the fittest. Our results also underline the need for uniformity in approach to measurement of PA, body composition and health-related fitness between studies.
\end{abstract}

\section{Background}

It is well established that physical activity (PA) is an important health determinant in young people. Sirard and Pate [1] reported an inverse relationship between PA and chronic diseases such as obesity, cancer, ischemia and coronary disease. Active children appear to be engaged in a sufficient variety of activities that enhance multiple components of health-related fitness [2]. The literature shows that a physically active lifestyle during childhood and adolescence may decrease the risk of having health problems during adulthood and that more active children tend to be more active adults $[3,4]$.

\footnotetext{
* Correspondence: georges.baquet@univ-lille2.fr

+ Contributed equally

'University of Lille Nord de France, UDSL, EA 4488, Physical Activity - Muscle - Health, Lille, France

Full list of author information is available at the end of the article
}

Thus, it is often assumed that PA and physical performance during childhood and adolescence are beneficial for health during adulthood [5], but a positive relationship between PA and physical performance has not been precisely clarified in children [6,7]. Although Katzmarzyk et al. [8] have reported a significant relationship between PA and health-related physical performance, they noticed that a large part of the variability (80-90\%) in performance is not accounted for by PA. The doseresponse relationship between physical activity and performance and health during childhood remains incomplete and is not fully understood [9]. The lack or the weakness of the relationships between PA and physical performance could be due to the measure of PA. From an observational study, Bailey et al. [10] have provided objective evidence on the highly transitory nature of children's PA. Thus questionnaires or monitoring

\section{Biomed Central}


children's PA with a 1-min sampling do not reflect the real patterns of children's physical activity. The use of accelerometry is considered as an objective (frequency, intensity and duration) and common measure of children's habitual PA [11]. Using such a device with a 2-s epoch, Baquet et al. [12] demonstrated that the mean PA bout duration lasted about 20s and that $95 \%$ of high intensity activities lasted less than 10s with a median duration of $4 \mathrm{~s}$. Moreover, if vigorous and very high intensity activity bouts represented $2.4 \%$ of the daily PA, they accounted for $36.1 \pm 5.8 \%$ of the amount of the total daily PA. Thus, monitoring with a 1 -min epoch does not discriminate between high and very high intensity PA that can be related to physical performance.

Thus, to assess in detail the PA patterns in children, a high frequency monitoring is needed [12,13]. These studies have reported the nature of children's spontaneous activity patterns, but not their impact on health outcomes and physical performance. In adults, Murphy et al. [14] reported that, at least for aerobic fitness, accumulated and continuous patterns of exercise training of the same total duration confer similar benefits. In boys, Stone et al. [15] showed that the frequency of short bouts of PA were strongly related with health than longer bouts and reported a significant relationship between PA patterns and peak of oxygen uptake. However, to our knowledge, it is not known if PA patterns (frequency, intensity and duration) are related to other physical performance in boys and in girls. Some physical performances (speed, explosive strength) could be related with PA bout frequency and intensity and other (aerobic fitness) with PA bout duration. Therefore, the purpose of the present study was to investigate the relationship between PA level (time spent in different PA intensity), PA patterns (number of bouts of PA according to their duration and intensity) and physical performance level in 6- to 12 - yearold children, through high frequency accelerometry monitoring.

\section{Methods}

\section{Participants}

At the beginning, two hundred and fourteen children (98 boys and 116 girls), aged 6 to 12, participated in this study. The children were taken from 16 elementary classes in the North of France. Full advice about possible risks and discomfort with the protocol was given to the children and their parents. All children gave their assent to take part in the study and all parents signed a written informed consent. The study was designed in accordance with the ethical standards of the Helsinki Declaration of 2008, and received approval of the local "Consultative Committee for the Protection of Persons in Biomedical Research".

\section{Anthropometry}

Height was measured to the nearest $0.1 \mathrm{~cm}$ with a wall stadiometer (Vivioz medical, Paris, France). Body mass was measured to the nearest $0.1 \mathrm{~kg}$ with a calibrated electronic balance (Tanita TBF 543, Tanita Inco, Iokyo, Japan). Waist and hip circumferences were measured with the subjects in a standing position with a non-elastic measuring tape. Waist circumference was measured at the midpoint between the lower border of the rib cage and the iliac crest, and hip circumference was measured at the widest part of the hip region. The waist/hip $(\mathrm{W} / \mathrm{H})$ ratio was then calculated. Percentage of body fat was estimated from skinfold (SF) thickness $(0.1 \mathrm{~mm})$. Measurements were assessed with a Harpenden caliper (Harpenden Inc.) at two sites (Triceps, and Calf). According to Slaughter et al. [16], the equations were: Estimated percentage of body fat $=0.735(\Sigma \mathrm{SF})+1.0$ and percentage of body fat $=0.61(\Sigma \mathrm{SF})+5.0$, for boys and girls, respectively.

\section{Physical Performance Assessment}

Prior to participating in the study, the children were fully familiarized with the testing procedures. The children performed seven field tests from the European Physical Fitness (EUROFIT) test battery. According to EUROFIT test battery recommendations [17], anthropometrics (hip and waist circumferences, percentage of body fat, height and weight) were included in the EUROFIT items. This battery was developed between 1976 and 1986 due to an initiative of the European Council. The goals of this battery were to establish standardized tests in Europe to help teachers to assess the physical performance of their pupils in schools and to help in measuring the health-related performance of the population. To comply with EUROFIT standards, the recommendations of the Committee of Experts on Sports Research [17] were followed. Mahoney and Boreham [18] reported that the EUROFIT tests were reproducible in primary schools (113 children, 7 to 11 yrsold, with a one month-interval assessment). The tests were the standing broad jump (SBJ, explosive strength, in $\mathrm{cm}$ ), the $10 \times 5$ meter shuttle run (SHR, speed and agility, in s), the sit-and-reach (SAR, flexibility, in $\mathrm{cm}$ ), the handgrip (HG, static strength, in kgf), the number of sit-ups in 30 seconds (SUP, abdominal muscular power), the 20-meter shuttle run (20-MST, maximal aerobic power, in $\left.\mathrm{km} \cdot \mathrm{h}^{-1}\right)$. Sixty randomly selected children (30 boys and 30 girls) performed the 20 -m shuttle run test with continuous heart rate (HR) monitoring (Polar Accurex+, Finland) to assess the maximality of the test (Table 1). A HR value above $195 \mathrm{bpm}$ was accepted as a maximal index, associated with visible exhaustion [19].

As recommended by the EUROFIT guidelines, the subjects performed the tests in the following order: SBJ, 
Table 1 Mean \pm SD for anthropometric measurements and EUROFIT performances in boys and girls

\begin{tabular}{ccc}
\hline & Boys $(\mathbf{n}=\mathbf{8 6})$ & Girls $(\mathbf{n}=\mathbf{1 0 1})$ \\
\hline Age $(\mathrm{yr})$ & $9.1 \pm 1.3$ & $9.1 \pm 1.3$ \\
Height $(\mathrm{cm})$ & $135.9 \pm 9.5$ & $135.7 \pm 10.3$ \\
Body mass $(\mathrm{kg})$ & $33.3 \pm 11.0$ & $32.0 \pm 8.0$ \\
Body mass index $\left(\mathrm{kg} \cdot \mathrm{m}^{-2}\right)$ & $17.6 \pm 3.4$ & $17.1 \pm 2.5$ \\
Hip/waist circumference ratio & $0.83 \pm 0.06$ & $0.81 \pm 0.05$ \\
\% BF (\%) & $15.1 \pm 5.5$ & $18.2 \pm 4,1^{* * *}$ \\
SBJ (cm) & $129.2 \pm 22.3$ & $128.9 \pm 23.6$ \\
SHR (s) & $21.5 \pm 2.6$ & $21.9 \pm 3.9$ \\
SAR (cm) & $15.0 \pm 6.1$ & $18.3 \pm 6.4^{* * *}$ \\
HG (kgf) & $15.6 \pm 4.5$ & $15.2 \pm 4.0$ \\
SUP (n) & $14.7 \pm 4.9$ & $14.9 \pm 4.3$ \\
20-MST (km.h ${ }^{-1}$ ) & $9.7 \pm 0.8$ & $9.7 \pm 0.7$ \\
& Boys $(n=30)$ & Girls $(n=30)$ \\
Maximal HR during 20-MST (bpm) & $200 \pm 9$ & $201 \pm 12$ \\
\hline
\end{tabular}

$\%$ BF: percentage of body fat; SBJ: standing broad jump; SHR: $10 \times 5 \mathrm{~m}$ shuttle run; SAR: sit and reach; HG: handgrip; SUP: number of Sit-ups; 20-MST: 20 meter shuttle run. Maximal HR during 20-MST: maximal heart rate during the $20 \mathrm{~m}$ shuttle run test.

***: significantly different between genders at $\mathrm{p}<0.001$

SHR, SAR, HG, SUP and 20-MST. Each test was separated by at least 15 -min. Testing was completed by all participants over one week.

\section{Physical Activity Assessment}

Children's physical activity was assessed using an uniaxial accelerometer, over a 7-day consecutive period (The Actigraph, Manufacturing Technologies, Inc., model 7164, Fort Walton Beach, FL). Only the children who completed at least a 6-day monitoring were included for further analysis. The Actigraph accelerometer facilitates the quantification of human motion (frequency and intensity) over a user-specified time interval called an epoch. The acceleration signal is digitized and the magnitude is summed over the epoch. At the end of each epoch duration, the summed value or activity "count" is stored in memory, and the integrator is reset. For this study, the epoch duration was set at 5-s, and data between 7 am and 9 pm were retained to subsequent analysis. The Actigraph used in this study has been shown to be a valid and reliable tool for quantifying PA in children [20].

To maximize the quality of the data, strategies were employed to encourage children compliance. Children received oral and written information to use the accelerometers comfortably: they wore the accelerometers on the right hip fastened with an elastic belt from waking up until bedtime. The accelerometer was removed during bathing and swimming. The investigators demonstrated to the parents and children, how to wear the device properly and reminded parents and children of the importance of not forgetting to wear it.
All the files were visually inspected to delete missing data. If the child had forgotten the device at any time of the day (morning, afternoon and evening), the file was rejected. A sequence of 120 zero counts (10 min recording) was defined as the level of missing data [21]. The 5 -s activity counts were uploaded to an Excel $^{\odot}$ macro to calculate the time spent below and above different PA thresholds, corresponding to light (LPA $<3$ METs), moderate (MPA, $3 \leq \mathrm{MPA}<6 \mathrm{METs}$ ), vigorous (VPA, 6 $\leq \mathrm{VPA}<9$ METs) and very high PA (VHPA $\geq 9$ METs). The Actigraph outputs of 162, 440 and 790 counts per $5 \mathrm{~s}$ were the cut-offs used to define 3, 6 and 9 METs, respectively [22]. Times spent below and above the different intensity thresholds were calculated for each of the 7 days. To examine continuous PA behavior patterns, the daily number of PA bouts of various durations [from 5 to $15 \mathrm{~s}$ ], [from 16 to $30 \mathrm{~s}$ ], [31 to $60 \mathrm{~s}$ ], [61 to $180 \mathrm{~s}$ ], [181 to $300 \mathrm{~s}$ ], [301 to $600 \mathrm{~s}$ ] and [> 600s] were calculated for each intensity level [12].

According to Strong et al. [7], the percentage of children who reached the PA international guideline (60 accumulated minutes from MPA to VHPA, each day a week) was calculated.

\section{Statistical analysis}

The normality distribution of the data was checked using the Kolmogorov-Smirnov test. The experimental values were expressed as mean \pm standard deviation (mean $\pm \mathrm{SD}$ ). A Student's $t$-test was used to identify differences between boys and girls in anthropometric data, times spent below and above the different intensity thresholds over time (one week); number of bouts according to their duration and intensity and the EUROFIT performances.

We hypothesized that physical activity would be significantly associated with physical fitness dimensions as assessed from physical performances. Some of these performances (speed, explosive strength) may be related with PA bout frequency and intensity and aerobic performance with PA bout duration. Univariate analyses were conducted to examine the relationships between PA, times spent at various PA intensities, and physical performance, using Pearson product moment correlations, adjusted for age and percentage of body fat. A multivariate stepwise regression analysis was developed a priori to account for variation for each physical performance with a correlation significant at a $0.2 \mathrm{p}$-level. Other PA variables were added to the basic model to determine which model explained the most variance with the fewest number of covariates. When significant relationships were observed between times spent at various PA intensities level and physical performance, relationships with the corresponding activity pattern variables were explored. 
Statistical analyses were conducted with Instat 3 (GraphPad software). The threshold for statistical significance was set at $\mathrm{p} \leq 0.05$.

\section{Results}

Although investigators and parents reminded children of the importance of wearing their device during the experimental period and tried to complete the measurement of physical performance, twenty-seven children (12 boys and 15 girls) were rejected for an incomplete PA data set or for absences in measured physical performances. One hundred and eighty-seven children (101 girls and 86 boys) were finally retained for the study.

\section{Anthropometry and physical performance}

Age, anthropometric data and physical performance are presented in Table 1 . The Student's $t$-test revealed no sex difference, except for a higher percentage of body fat and a higher flexibility in girls $(\mathrm{p}<0.001)$.

\section{Physical activity}

For boys and girls, the daily PA time spent at different intensity levels is presented in Table 2. Girls spent more time in LPA than boys $(+17.4 \mathrm{~min}, p<0.001)$, whilst the latter spent more time in MPA $(+12.6 \mathrm{~min}, \mathrm{p}<$ $0.001)$ and in VPA $(+3.5 \mathrm{~min}, p<0.01)$. No sex-related difference was found for time spent in VHPA. Boys (95.3\%) were more likely to attain $(\mathrm{p}<0.05)$ the current PA guidelines (i.e. accumulating at least $60 \mathrm{~min}$ of moderate to vigorous PA per day) than the girls (77.5\%).

For the whole population, the mean duration of PA bouts was $95.4 \pm 22.2 \mathrm{~s}$ for LPA, $13.6 \pm 2.8 \mathrm{~s}$ for MPA, $8.3 \pm 0.9 \mathrm{~s}$ for VPA and $6.9 \pm 0.7 \mathrm{~s}$ for VHPA. Girls showed $(\mathrm{p}<0.001)$ longer LPA bouts $(100.3 \pm 1.6 \mathrm{~s})$ than, the boys $(89.5 \pm 20.8 \mathrm{~s})$, while boys showed $(\mathrm{p}<$ $0.001)$ longer MPA bouts $(14.8 \pm 2.6 \mathrm{~s})$ than the girls $(12.7 \pm 1.6 \mathrm{~s})$. No gender difference was found for VPA and VHPA mean duration bouts.

Table 3 displayed the distribution of PA bouts according to their intensity and duration. As intensity increased from LPA to VHPA, there was a steady decrease in the frequency of bouts as a function of their respective durations. Girls showed significantly more 1to 10-min LPA bouts than the boys $(\mathrm{p}<0.01)$. Boys presented significantly more 16 -s to 3 -min MPA bouts ( $\mathrm{p}<$
0.001), more VPA bouts inferior to 30-s $(\mathrm{p}<0.05)$ and more VHPA bouts shorter than $15-\mathrm{s}(\mathrm{p}<0.001)$ than the girls.

\section{Relation between physical activity and EUROFIT tests}

Relationships between physical performance and times spent at PA intensity levels are presented in Table 4. For girls, no aspect of physical performance was related to PA. In boys, percentage of body fat was positively correlated with LPA $(\mathrm{r}=0.28, \mathrm{p}<0.01)$ and negatively with VPA and VHPA $(\mathrm{r}=-0.38, \mathrm{p}<0.001$ and $\mathrm{r}=$ $-0.35, \mathrm{p}<0.01$, respectively). No relationship was found between time spent in MPA and physical performance.

The multivariate stepwise regression analysis was developed to account for variation in percentage of body fat for boys, and, in SUP and 20-MST for girls. Only a significant relationship was found for body fatness in boys $\left(\mathrm{r}^{2}=0.20, \mathrm{p}<0.01\right)$. VPA makes a significant contribution to the model, while LPA and MPA provided redundant information. LPA was not included in the model (Table 5).

Relationships between PA patterns and physical performance are presented in Table 6 . In boys, long bouts of LPA (>600s) were positively related to higher percentage of body fat $(r=0.34, p<0.01)$, while negative correlations were found with short and medium bouts of LPA ( 5 to $180-\mathrm{s}$, from $\mathrm{r}=-0.31, \mathrm{p}<0.01$ to $\mathrm{r}=-0.23$, $\mathrm{p}$ $<0.05$ ), VPA (5 to 60-s, from $\mathrm{r}=-0.44, \mathrm{p}<0.001$ to $\mathrm{r}=$ $-0.25, \mathrm{p}<0.05$ ) and VHPA (5 to 60-s, from $\mathrm{r}=-0.39, \mathrm{p}$ $<0.001$ to $\mathrm{r}=-0.24, \mathrm{p}<0.05$. A multivariate stepwise regression analysis was developed to account for variation in percentage of body fat for boys. A significant relationship was found for percentage of body fatness in boys $\left(\mathrm{r}^{2}=0.26, \mathrm{p}<0.001\right)$. Short bouts of VPA (from 5 to $15 \mathrm{~s})$ make a significant contribution to the model (Table 7).

\section{Discussion}

This study investigated the relationship between physical performance and PA patterns in prepubertal children by means of EUROFIT tests and high frequency accelerometry measurement. The main finding is that the physical performance was not related to physical activity level in 6- to 12-yr-old children. Only a trivial negative relationship between PA level and body fatness was

Table 2 Mean \pm SD for daily times spent at various PA intensity levels between 7 am to 9 pm and percentage of boys and girls who reached the international PA guideline [7]

\begin{tabular}{cccccc}
\hline & LPA $(\min )$ & MPA $(\boldsymbol{m i n})$ & VPA $(\boldsymbol{m i n})$ & VHPA $(\min )$ & $\geq 60$ min MPA to VHPA (\%) \\
\hline Boys $(n=86)$ & $745.6 \pm 24.4^{* * *}$ & $69.5 \pm 16.6^{* * *}$ & $16.3 \pm 6.4^{* *}$ & $7.6 \pm 3.9$ & 95.3 \\
Girls $(n=101)$ & $763.0 \pm 21.1$ & $56.9 \pm 14.2$ & $12.8 \pm 5.2$ & $6.5 \pm 5.4$ & 77.5 \\
\hline
\end{tabular}

LPA: light physical activity; MPA: moderate physical activity; VPA: vigorous physical activity; VHPA: very high physical activity. $\geq 60$ min MPA to VHPA (\%): percentage of children which accumulated more than 60 min MPA to VHPA.

**: significantly different between genders at $p<0.01$; **: significantly different between genders at $p<0.001$. 
Table 3 Mean \pm SD for the daily number of continuous bouts of physical activity according to their duration and intensity

\begin{tabular}{|c|c|c|c|c|c|c|c|c|}
\hline & \multicolumn{2}{|c|}{ LPA } & \multicolumn{2}{|c|}{ MPA } & \multicolumn{2}{|c|}{ VPA } & \multicolumn{2}{|c|}{ VHPA } \\
\hline & Boys & Girls & Boys & Girls & Boys & Girls & Boys & Girls \\
\hline$\leq 15 \mathrm{~s}$ & $214.4 \pm 63.9^{* * *}$ & $174.3 \pm 55.6$ & $344.8 \pm 79.1$ & $336.3 \pm 76.7$ & $157.9 \pm 53.4^{* * *}$ & $125.3 \pm 48.4$ & $59.9 \pm 25.8^{* * *}$ & $44.1 \pm 27.9$ \\
\hline $15<x \leq 30 s$ & $63.1 \pm 16.3$ & $60.5 \pm 17.0$ & $49.8 \pm 14.9^{* * *}$ & $38.7 \pm 12.9$ & $9.4 \pm 5.2^{* * *}$ & $7.0 \pm 5.5$ & $1.8 \pm 1.7$ & $1.8 \pm 2.2$ \\
\hline $30<x \leq 60 s$ & $51.5 \pm 12.6$ & $53.9 \pm 12.5$ & $22.3 \pm 8.5^{* * *}$ & $14.5 \pm 6.3$ & $1.9 \pm 1.3$ & $1.8 \pm 1.8$ & $0.3 \pm 0.5$ & $0.5 \pm 0.9$ \\
\hline $60<x \leq 180 s$ & $52.1 \pm 11.5$ & $58.9 \pm 11.0^{* * *}$ & $7.3 \pm 3.4^{* * *}$ & $4.3 \pm 2.5$ & $0.07 \pm 0.1$ & $0.1 \pm 0.3$ & $0.1 \pm 0.2$ & $0.2 \pm 0.4$ \\
\hline $180<x \leq 600 s$ & $27.6 \pm 5.8$ & $31.2 \pm 5.1^{* * *}$ & $0.5 \pm 0.5$ & $0.5 \pm 0.6$ & $0.02 \pm 0.08$ & $0.003 \pm 0.02$ & $0.004 \pm 0.02$ & $0.03 \pm 0.1$ \\
\hline$>600 s$ & $14.6 \pm 2.9$ & $14.6 \pm 2.5$ & $0.02 \pm 0.7$ & $0.02 \pm 0.01$ & $0.002 \pm 0.02$ & $0.005 \pm 0.05$ & & \\
\hline
\end{tabular}

LPA: light physical activity; MPA: moderate physical activity; VPA: vigorous physical activity; VHPA: very high physical activity.

***: significantly different between genders at $p<0.001$.

observed in boys with short bouts of VPA (from 5 to $15 \mathrm{~s})$ that made a significant contribution in percentage body fat variation as demonstrated by the multivariate analysis.

From childhood to adolescence, the literature has generally shown a weak to moderate relationship between PA and physical performance [23]. We hypothesized that high frequency accelerometry monitoring $(5 \mathrm{~s}$ epoch) should be able to provide a more accurate measurement of children PA behaviors, notably to capture short bouts of VPA and VHPA that are generally diluted in PA measurement when accelerometer epoch is set at $1 \mathrm{~min}$. In the current study, no relationship was found between PA and physical performance. As observed in adults [24], these results suggests that habitual activity did not show adequate intensity, volume, and duration to induce positive changes in motor and functional capacities. Indeed, VPA or VHPA are generally considered as the upper boundaries of physical activity domains in the context of health related studies. The cut off used in the present study for VPA and VHPA were derived from counts values associated with velocities of $6.4 \mathrm{~km} \cdot \mathrm{h}^{-1}$ (6 METs) and $9.7 \mathrm{~km} \cdot \mathrm{h}^{-1}(9 \mathrm{METs})$, respectively. However, these intensities of exercise remain largely lower than those reached in the context of performance. For instance, in the present study, the running velocity associated with 20-MST performance (around $10 \mathrm{~km} \cdot \mathrm{h}^{-1}$ ) was certainly not sustained for sufficient long periods to expect an improvement in aerobic fitness. Similarly, a $9.7 \mathrm{~km} . \mathrm{h}^{-1}$ velocity (VHPA) remained two times lower than a sprint velocity in such a population that is around $20 \mathrm{~km} \cdot \mathrm{h}^{-1}$. Thus, it could be hypothesized that systematic training and not time spent in VPA or VHPA is needed to increase physical performances such as SBJ, SHR or 20-MST.

Only for boys, time spent in LPA was positively correlated with body fatness, whereas VPA and VHPA were negatively associated. Rowlands et al. [25] reported a negative relationship between fatness and PA in 8- to 10-yr-old boys and girls, whilst Dencker and Andersen [26] reported only low to moderate inverse relationships between moderate to vigorous PA and body fatness with a comparable population. Using accelerometry, Abbott and Davies [27] and Dencker et al. [28] found significant relationships between VPA and VHPA and body fatness, but no relationship was reported with MPA. These

Table 4 Correlations between the times spent at various intensity levels, anthropometry and EUROFIT performances for the boys and the girls.

\begin{tabular}{cccccccccccc}
\hline Boys & $\begin{array}{c}\text { Height } \\
(\mathbf{c m})\end{array}$ & $\begin{array}{c}\text { Weight } \\
(\mathbf{k g})\end{array}$ & $\begin{array}{c}\text { BMI } \\
\left(\mathbf{k g} \cdot \mathbf{m}^{-2}\right)\end{array}$ & H/W & \% BF & $\begin{array}{c}\text { SBJ } \\
(\mathbf{c m})\end{array}$ & $\begin{array}{c}\text { SHR } \\
(\mathbf{s})\end{array}$ & $\begin{array}{c}\text { SAR } \\
(\mathbf{c m})\end{array}$ & $\begin{array}{c}\text { HG } \\
(\mathbf{k g f})\end{array}$ & $\begin{array}{c}\text { SUP } \\
(\mathbf{n})\end{array}$ & $\begin{array}{c}\mathbf{2 0}-\mathbf{M S T} \\
\left(\mathbf{k m} \cdot \mathbf{h}^{-1}\right)\end{array}$ \\
\hline LPA & -0.06 & 0.06 & -0.11 & -0.04 & $0.28^{* *}$ & -0.11 & 0.18 & -0.07 & -0.08 & -0.15 & -0.08 \\
MPA & 0.08 & -0.02 & -0.06 & 0.04 & -0.19 & 0.06 & -0.15 & 0.02 & 0.11 & 0.11 & 0.08 \\
VPA & 0.04 & -0.09 & -0.15 & 0.05 & $-0.38^{* * *}$ & 0.18 & -0.18 & 0.12 & 0.03 & 0.20 & 0.08 \\
VHPA & 0.06 & -0.06 & -0.12 & -0.02 & $-0.35^{* *}$ & 0.18 & -0.19 & 0.08 & -0.004 & 0.21 & 0.06 \\
\hline Girls & & & & & & & & & & & \\
\hline LPA & -0.05 & -0.08 & -0.08 & -0.06 & 0.03 & 0.10 & 0.05 & -0.04 & -0.03 & $-0.12+$ & -0.10 \\
MPA & 0.02 & 0.06 & 0.08 & 0.09 & -0.01 & -0.15 & -0.02 & 0.07 & 0.02 & $0.12+$ & 0.10 \\
VPA & 0.04 & 0.05 & 0.05 & 0.04 & -0.04 & -0.08 & -0.07 & -0.01 & -0.001 & 0.11 & $0.16+$ \\
VHPA & $-0.19+$ & $-0.18 \dagger$ & 0.12 & -0.01 & $-0.15+$ & -0.16 & 0.08 & -0.05 & -0.14 & -0.08 & -0.01 \\
\hline
\end{tabular}

LPA: light physical activity; MPA: moderate physical activity; VPA: vigorous physical activity; VHPA: very high physical activity. BMI: body mass index; H/W: hip/ waist circumference ratio; $\%$ BF: percentage of body fat; SBJ: standing broad jump; SHR: $10 \times 5 \mathrm{~m}$ shuttle run; SAR: sit and reach; HG: handgrip; SUP: number of sit-ups; MS: maximal shuttle speed.

${ }^{* *}: p<0.01$ significance; ${ }^{* *}: p<0.001$ significance; $+: p<0.2$. 
Table 5 Variables (times spent at various PA intensities) explaining the percentage of body fat in boys

\begin{tabular}{|c|c|c|}
\hline \multirow{3}{*}{$R^{2}$ (SEE) } & \multicolumn{2}{|c|}{$\% B F$} \\
\hline & \multicolumn{2}{|c|}{$0.20(5.09)$} \\
\hline & Estimates & $P$ values \\
\hline Age & $0.05(-0.02-0.12)$ & 0.172 \\
\hline MPA & $0.02(-0.05-0.09)$ & 0.547 \\
\hline VPA & $-0.29(-0.52--0.05)$ & 0.018 \\
\hline VHPA & $-0.27(-0.62-0.08)$ & 0.13 \\
\hline
\end{tabular}

\%BF: percentage of body fat; MPA: moderate physical activity; VPA: vigorous physical activity; VHPA: very high physical activity; SEE: standard error of the estimate. Confidence intervals: $95 \%$ of estimates are displayed in brackets.

findings agree with the present study, where trivial relationships between VPA and VHPA and body fatness were also observed. Conversely, Ness et al. [29] reported higher correlations between moderate to vigorous PA and body fatness in boys of comparable ages. These differences could be explained by an acute measure of fat mass (dual x-ray emission absorptiometry) in the latter study, while skinfold measurement, as used in the present study, remains a less robust method. Nevertheless, the weak relationship found between LPA and percentage body fat in boys only, should also be carefully interpreted. The cut-offs used [22] in the present study do not allow to differentiate between LPA and sedentary activity, the latter being included in LPA. Body fatness in boys may thus be more related to sedentary activity than to LPA. Few recent studies proposed thresholds to discriminate between LPA and sedentary activity [30-32] but none of them used a $5 \mathrm{~s}$ - epoch. It is possible that the 5-s epoch might not be appropriate to assess "true" sedentary activities. Indeed, this type of activity would better assessed with longer epochs such as 1-min rather than 5-s epoch. The latter could lead to an overestimation of sedentary activity. For example, during spontaneous PA, where children alternate short bouts of PA with short recovery periods, the recovery bout would be classified as sedentary activity, whereas it is not.

Table 6 Correlations between the number of bouts according to their duration and intensity and percentage of body fat in boys.

\begin{tabular}{|c|c|c|c|c|c|c|}
\hline & & $\%$ BF & & $\%$ BF & & $\% \mathrm{BF}$ \\
\hline$\leq 15 \mathrm{~s}$ & & $-0.31^{* *}$ & & $-0.44^{* * *}$ & & $-0.39 * * *$ \\
\hline $15<x \leq 30 s$ & & $-0.30^{*}$ & & $-0.38^{*}$ & & $-0.26^{*}$ \\
\hline $30<x \leq 60 s$ & LPA & $-0.25^{*}$ & VPA & $-0.25^{*}$ & VHPA & $-0.24^{*}$ \\
\hline $60<x \leq 180 s$ & & $-0.23^{*}$ & & -0.02 & & -0.09 \\
\hline $180<x \leq 600 s$ & & -0.10 & & -0.02 & & -0.04 \\
\hline$>600 s$ & & $0.34^{* *}$ & & & & \\
\hline
\end{tabular}

LPA: light physical activity; VPA: vigorous physical activity; VHPA: very high physical activity; $\%$ body fat: percentage of body fat.

${ }^{*}: p<0.05$ significance; ${ }^{* *}: p<0.01$ significance; ${ }^{* * *}: p<0.001$ significance.
Table 7 Variables (number of bouts according to their duration and their intensity) explaining the percentage of body fat in boys

\begin{tabular}{ccc}
\hline & \% BF \\
\hline$R^{2}(S E E)$ & Estimates & $P$ values \\
Age & $0.03(-0.05-0.11)$ & 0.51 \\
LPA $\leq 15 \mathrm{~s}$ & $0.02(-0.02-0.05)$ & 0.31 \\
LPA $>600 \mathrm{~s}$ & $0.42(-0.012-0.96)$ & 0.13 \\
VPA $\leq 15 \mathrm{~s}$ & $-0.05(-0.08--0.14)$ & 0.006 \\
VHPA 30 $<x \leq 60 \mathrm{~s}$ & $-1.57(-3.84-0.71)$ & 0.17 \\
\hline
\end{tabular}

LPA: light physical activity; VPA: vigorous physical activity; VHPA: very high physical activity; \%BF: percentage of body fat; SEE: standard error of the estimate. Confidence intervals: $95 \%$ of estimates are displayed in brackets

Relationships between waist circumference and body composition seem to be associated with cardiovascular disease risk and suggested that PA may have a beneficial effect, notably with respect to overweight $[33,34]$. In the present study, no relationship was found between hip and waist circumferences and times spent from LPA to VHPA. Using accelerometry, Hussey et al. [35] reported a significant negative correlation between waist circumference and time spent in VPA in boys, but not in girls. Similar conclusions were drawn by Ness et al. [29].

In the literature, positive relationships between PA and aerobic fitness have generally been observed in children $[25,26]$. However, correlations reported in the literature are moderate, therefore Dencker et al. [26] suggested that the aerobically fitter children were not obligatorily the more active. The results found in the current study showed that aerobic fitness was not associated with overall physical activity. Differences between experimental protocols (epoch length and/or field vs laboratory tests) may explain these discrepancies.

Children's PA is characterized by rapid changes from rest to PA including vigorous intensities. Investigating PA patterns related to health gives information about how to promote PA during childhood. To the best of our knowledge, only one study [15] has investigated the relationship between PA patterns and physical fitness. They reported that children's sporadic activity was negatively related to waist circumference and aerobic fitness. In the present study, short bouts of VPA in boys were positively related to lower body fatness, whereas LPA and sedentary long bouts were negatively associated. Our results show that PA intensity has a positive influence on the maintenance of a healthy body composition and suggest that children should be engaged in longer VPA sessions. As the majority of children's VPA and VHPA is accumulated via short intermittent bouts rather than long continuous bouts, intermittent activity seems to be efficient to promote healthy body composition and health-related fitness. However, there is an 
urgent need for more longitudinal studies on children in which PA, physical fitness (or performance), and health are measured repeatedly in the same individual over an extended period of time [36,37].

More than ninety-five percent of the boys and $77.5 \%$ of the girls accumulated 60 or more minutes of moderate to very high PA per day. These results are higher than reported on UK children [15], but lower compared with some American or European studies [21,38]. However, the proportion of children reaching PA guidelines should be interpreted with caution. The use of higher accelerometer thresholds to classify intensity or the use of a smaller epoch to monitor PA might explain these discrepancies between studies.

Times spent from MPA to VHPA were lower than reported in the literature. Girls spent more time in LPA than boys $(2.1 \%, \mathrm{p}<0.001)$, whilst the latter spent more time in MPA $(1.5 \%, \mathrm{p}<0.001)$ and in VPA $(0.4 \%, p<$ $0.05)$. A sex-related difference was only found for 5 to 10-s VHPA bouts $(\mathrm{p}<0.001)$. Hussey et al. [35] assessed PA during 4 days on Irish children aged 7 to 10 . They observed that boys spent twice as much VPA and VHPA as girls $(64.3 \mathrm{~min}$ vs $37 \mathrm{~min}$ each day, $\mathrm{p}<0.001)$. Trost et al. [39] reported that boys spent about $120 \mathrm{~min}$ in MPA, whereas girls spent $100 \mathrm{~min}$ per day $(\mathrm{p}<0.05)$. These differences may be explained by the use of different accelerometers [35,40]; different epochs [21,39]; number of the monitoring days [41] and different cut-offs [30]. In the present study a 5-s epoch was used to assess more accurately children's PA patterns in free-living conditions. Vigorous PA and VHPA are captured and not diluted in MPA or LPA. Using a 2-s epoch, Rowlands et al. [13] reported that differences in PA were largely due to the intensity of the most frequent bouts of activity and the frequency of the most intense bouts. McClain et al. [42] also reported that shorter epoch lengths should be used to minimize error among individual estimates.

\section{Conclusion}

In 6- to- 12 yr- old children, the children's PA level is poorly related to the physical performance. Only a trivial relationship between vigorous physical activity and body fatness was observed. Our results also underline the need for uniformity in approach to measurement of PA, body composition and health-related fitness between studies.

\section{Acknowledgements}

The authors would like to acknowledge the teachers and children from the primary schools of Illies, Herlies and Santes (North of France).

\section{Author details}

'University of Lille Nord de France, UDSL, EA 4488, Physical Activity - Muscle - Health, Lille, France. ${ }^{2}$ Blaise Pascal University, UFR STAPS, Laboratory of Exercise Biology (BAPS), EA 3533, Clermont-Ferrand, France.

\section{Authors' contributions}

$A B$ and $G B$ were involved in acquisition, analysis, and interpretation of data, drafting and manuscript writing. SB was involved in analysis and interpretation of data, drafting and critically revising the manuscript. CF and EVP were involved in the conception and design of the paper and played a role in critically revising and editing the manuscript. All authors read and approved the final manuscript.

\section{Competing interests}

The authors declare that they have no competing interests.

Received: 16 September 2010 Accepted: 4 November 2011

Published: 4 November 2011

\section{References}

1. Sirard JR, Pate RR: Physical activity assessment in children and adolescents. Sports Med 2001, 31(6):439-454

2. Sallis JF, McKenzie TL, Alcaraz JE: Habitual physical activity and healthrelated physical fitness in fourth-grade children. Am J Dis Child 1993, 147(8):890-896.

3. Telama R, Yang X, Laasko L, Viikari J: Physical activity in childhood and adolescence as predictor of physical activity in young adulthood. Am J Prev Med 1997, 13(4):317-323.

4. Trudeau F, Laurencelle L, Tremblay J, Rajie M, Shephard RJ: A long-term follow-up of participants in the Trois Rivières semi-longitudinal study of growth and development. Pediatr Exerc Sci 1998, 10(4):366-377.

5. Blair SN, Kohl HW, Paffenbarger RS, Clark DG, Cooper KH, Gibbons LW: Physical fitness and all cause mortality point prospective study of healthy men and women. JAMA 1999, 262(17):2395-2401.

6. Riddoch CJ, Boreham C: Physical activity physical fitness and children's health: current concepts. In Pediatric Exercise and Medicine. Edited by: Armstrong N, Van Mechelen W. Oxford: Oxford University Press; 2000:243-252.

7. Strong WB, Malina RM, Blimkie CJR, Daniels SR, Dishman RK, Gutin B, Hergenroeder AC, Must A, Nixon PA, Pivarnik JM, Rowland TW, Trost SG, Trudeau F: Evidence based physical activity for school-age youth. J Pediatr 2005, 146:732-737.

8. Katzmarzyk PT, Malina RM, Song TM, Bouchard C: Physical activity and health-related fitness in youth: a multivariate analysis. Med Sci Sports Exerc 1998, 30(5):709-714

9. Lee IM: Dose-response relation between physical activity and fitness: even a little is good; more is better. JAMA 2007, 297(19):2137-2139.

10. Bailey RC, Olson J, Pepper SL, Porszasz J, Barstow TJ, Cooper DM: The level and tempo of children's physical activities: an observational study. Med Sci Sports Exerc 1995, 27(7).

11. Troiano RP: Large-scale applications of accelerometers: new frontiers and new questions. Med Sci Sports Exerc 2007, 39(9):1501.

12. Baquet G, Stratton G, Van Praagh E, Berthoin S: Improving physical activity assessment in prepubertal children with high-frequency accelerometry monitoring: a methodological issue. Prev Med 2007, 44(2):143-147.

13. Rowlands AV, Pilgrim EL, Eston RG: Patterns of habitual activity across weekdays and weekend days in 9-11-year-old children. Prev Med 2008, 46(4):317-324.

14. Murphy $\mathrm{MH}$, Blair SN, Murtagh EM: Accumulated versus continuous exercise for health benefit: a review of empirical studies. Sports Med 2009, 39(1):29-43.

15. Stone MR, Rowlands AV, Middlebrooke AR, Jawis MN, Eston RG: The pattern of physical activity in relation to health outcomes in boys. Int $J$ Pediatr Obes 2009, 4(4):306-315.

16. Slaughter MH, Lohman TG, Boileau RA, Horswill CA, Stillman RJ, Van Loan MD, Bemben DA: Skinfold equations for estimation on body fatness in children and youth. Hum Biol 1988, 60:709-723.

17. Committee of Experts on Sports Research: Handbook for the EUROFIT tests of physical fitness Rome: Edigraf Editoriale Grafica; 1988.

18. Mahoney C, Boreham C: Validity and reliability of fitness testing in Primary School. In Fitness Testing and Primary School Children Sport and Physical Activity. Edited by: Williams TJ, et al. London: E and FN Spon; 1992:429-437.

19. Tolfrey K, Campbell IG, Batterham AM: Aerobic trainability of prepubertal boys and girls. Pediatr Exerc Sci 1998, 10:248-263. 
20. De Vries S, Van Hirtum WJEM, Bekker I, Hopman-Rock M, Hirasing RA, Van Mechelen W: Validity and Reproducibility of Motion Sensors in Youth: A Systematic Update. Med Sci Sports Exerc 2009, 41(4):818-827.

21. Riddoch CJ, Andersen LB, Wedderkopp N, Harro M, Klasson-Heggebo L, Sardinha LB, Cooper AM, Ekelund U: Physical activity levels and patterns of 9- and 15-yr-old European children. Med Sci Sports Exerc 2004, 36(1):86-92.

22. Nilsson A, Ekelund U, Yngve A, Sjöström N: Assessing physical activity among children with accelerometers using different time sampling intervals and placements. Pediatr Exerc Sci 2002, 14:87-96.

23. Malina RM: Adherence to physical activity from childhood to adulthood: a perspective from tracking studies. Quest 2001, 53:346-355.

24. Ruzic L, Heimer S, Misigoj-Durakovic M, Matkovic BR: Increased occupational physical activity does not improve physical fitness. Occup Environ Med 2003, 60(12):983-985.

25. Rowlands AV, Roger G, David K: Relationship between activity levels, aerobic fitness and body fat in 8- to 10-yr-old children. J Appl Physiol 1999, 86(4):1428-1435.

26. Dencker M, Andersen LB: Health-related aspects of objectively measured daily physical activity in children. Clin Physiol Funct Imaging 2008, 28:133-134.

27. Abbott RA, Davies PS: Habitual physical activity and physical activity intensity: their relation to body composition in 5.0-10.5-y-old children. Eur J Clin Nutr 2004, 58(2):285-291.

28. Dencker $M$, Thorsson $O$, Karlsson M, Lindén C, Eiberg S, Wollmer $P$, Andersen LB: Daily physical activity related to body fat in children aged 8-11 years. J Pediatr 2006, 149:38-42.

29. Ness AR, Leary SD, Mattocks C, Blair SN, Reilly JJ, Wells J, Ingle S, Tilling K, Smith GD, Riddoch C: Objectively measured physical activity and fat mass in a large cohort of children. PLoS Medicine 2007, 4(3):e97.

30. Puyau MR, Adolph AL, Vohra FA, Butte NF: Validation and calibration of physical activity monitors in children. Obes Res 2002, 10(3):150-157.

31. Trost SG, Mclver KL, Pate RR: Conducting accelerometer-based activity assessments in field-based research. Med Sci Sports Exerc 2005, 37(11):531-543.

32. Pulsford RM, Cortina-Borja M, Rich C, Kinnafick FE, Dezateux C, Griffiths LJ: Actigraph accelerometer-defined boundaries for sedentary behaviour and physical activity intensities in 7 year old children. PLOS One 2011, 6(8):e21822

33. Andersen LB, Sardinha LB, Froberg K, Riddoch CJ, Page AS, Anderssen SA: Fitness fatness and clustering of cardiovascular risk factors in children from Denmark, Estonia and Portugal: the European Youth Heart Study. Int J Pediatr Obes 2008, 1:58-66.

34. Klein-Platat C, Oujaa M, Wagner A, Haan MC, Arveiler D, Schlienger JL, Simon C: Physical activity is inversely related to waist circumference in 12-y-old children. Int J Obes 2005, 29(1):9-14.

35. Hussey J, Bell C, Benett K, O'Dwyer J, Gormley J: Relationship between the intensity of physical activity inactivity cardiorespiratory fitness and body composition in 7 to 10-year-old Dublin children. Br J Sports Med 2007, 41:311-316.

36. Kemper HCG: Amsterdam Growth and Health Longitudinal Study (A 23year follow-up from teenager to adult about lifestyle and health). In Medicine and Sport Science. Volume 47. Basel: Karger; 2004.

37. Matton L, Thomis M, Wijndaele K, Duvigneaud N, Beunen G, Claessens AL, Vanreusel B, Philippaerts R, Lefevre: Tracking of physical fitness and physical activity from youth to adulthood in females. Med Sci Sports Exerc 2006, 38(6):1114-1120.

38. Pate RR, Freedson PS, Sallis JF, Taylor WC, Sirard J, Trost SG, Dowda M: Compliance with physical activity guidelines: prevalence in a population of children and youth. Ann Epidemiol 2002, 12(5):303-308.

39. Trost SG, Pate RR, Sallis JF, Freedson PS, Taylor WC, Dowda M, Sirard J: Age and gender differences in objectively measured physical activity in youth. Med Sci Sports Exerc 2002, 34:350-355.

40. Rowlands AV, Thomas PW, Eston RG, Topping R: Validation of the RT3 triaxial accelerometer for the assessment of physical activity. Med Sci Sports Exerc 2004, 36(3):518-524.

41. Trost SG, Pate RR, Freedson PS, Sallis JF, Taylor WC: Using objective physical activity measures with youth: How many days of monitoring are needed? Med Sci Sports Exerc 2000, 32(2):426-431.
42. McClain JJ, Abraham TL, Brusseau TA Jr, Tudor-Locke C: Epoch length and accelerometer outputs in children: comparison to direct observation. Med Sci Sports Exerc 2008, 40(12):2080-2087.

doi:10.1186/1479-5868-8-122

Cite this article as: Blaes et al:: Is there any relationship between physical activity level and patterns, and physical performance in children? International Journal of Behavioral Nutrition and Physical Activity $20118: 122$

\section{Submit your next manuscript to BioMed Central and take full advantage of:}

- Convenient online submission

- Thorough peer review

- No space constraints or color figure charges

- Immediate publication on acceptance

- Inclusion in PubMed, CAS, Scopus and Google Scholar

- Research which is freely available for redistribution

Submit your manuscript at www.biomedcentral.com/submit
Biomed Central 